\title{
Circulating Fibrocytes Are Increased in Children and Young Adults with Pulmonary Hypertension
}

M.E. Yeager, ${ }^{1,3}$, C.M. Nguyen ${ }^{1}$, D.D. Belchenko ${ }^{1}$, K. L. Colvin², S. Takatsuki ${ }^{3}$, D.D. Ivy², and K.R. Stenmark ${ }^{1,3,4}$

${ }^{1}$ Department of Pediatrics, Division of Pulmonary, and Critical Care Medicine, University of Colorado Denver, Aurora, Colorado; ${ }^{2}$ The Pulmonary Hypertension Program and Section of Cardiology, Department of Pediatrics, The University of Colorado, Denver and The Children's Hospital, Denver, Colorado; ${ }^{3}$ Cardiovascular Pulmonary Research, ${ }^{4}$ Gates Center for Regenerative Medicine and Stem Cell Biology

\begin{abstract}
Chronic inflammation is an important component of the fibroproliferative changes that characterize pulmonary hypertensive vasculopathy. Fibrocytes contribute to tissue remodeling in settings of chronic inflammation, including animal models of pulmonary hypertension. We sought to determine if circulating fibrocytes were increased in children and young adults with pulmonary hypertension.
\end{abstract}

26 individuals with pulmonary hypertension and 10 with normal cardiac anatomy were studied. Fresh blood was analyzed by flow cytometry for fibrocytes expressing CD45 and procollagen. Fibrocyte numbers were correlated to clinical and hemodynamic parameters, and circulating CCL2 and CXCL12 levels.

We found enrichment of circulating fibrocytes among those with pulmonary hypertension. No differences were observed in fibrocytes among those with idiopathic $\mathrm{PH}$ vs. secondary $\mathrm{PH}$. 
Higher fibrocytes correlated to increasing mean pulmonary artery pressure and age, but not to length or type of treatment. Immunofluorescence analysis confirmed flow sorting specificity. Differences in plasma levels of CCL2 or CXCL12, which could mobilize fibrocytes from the bone marrow, were not found.

We conclude that circulating fibrocytes are significantly increased in individuals with pulmonary hypertension compared to controls. We speculate that these cells might play important roles in the vascular remodeling in children and young adults with pulmonary hypertension.

\section{List of Keywords}

vascular remodeling; fluorescent activated cell sorting; progenitor cells; inflammation; mononuclear phagocyte

\section{Introduction}

Chronic pulmonary hypertension $(\mathrm{PH})$ is distinguished by cellular and structural changes in the walls of pulmonary arteries. Intimal thickening and fibrosis, medial hypertrophy and fibroproliferative changes in the adventitia are common (1). In adults and children (2), virtually all of these changes are characterized by increased numbers of cells expressing alpha-smooth muscle actin and by perivascular accumulation of inflammatory cells (3-4). The source of these cells remains unclear but an origin from circulating progenitors has been postulated (4-5). In adults, the number and differentiation capability of endothelial progenitor cells (EPC) has been examined, though no consensus has been achieved as to a role for these cells in the pathogenesis of the disease (6-7). There is less data available regarding circulating cells of any kind in children and young adults with $\mathrm{PH}$. Recently, it was reported that while no significant differences in early or late EPC endothelial colony forming cells exists between reversible and irreversible $\mathrm{PH}$ (8), late EPC were found to be increased in children receiving treprostinil 
compared to those on endothelin receptor antagonists or phosphodiesterase inhibitors (6). These cells had increased angiogenic and hyperproliferative potential, which was hypothesized to partly explain the clinical benefits of prostanoids in pulmonary arterial hypertension. Nevertheless, severe pulmonary hypertension is confoundingly associated with vascular pruning in the periphery with concomitant inflammation, hypertrophy, and hyperplasia in larger bronchovascular structures (1). Periarterial infiltrates of macrophages and T lymphocytes have been documented in the setting with $\mathrm{PH}$ (9). Within similar inflammatory infiltrates in hypoxic animals, c-kit+ progenitor cells have also been identified (10-11). The origin of, and precise mechanisms by which, inflammatory/progenitor cells contribute to pulmonary vascular remodeling and inflammation observed in children and young adults with $\mathrm{PH}$ have not been thoroughly investigated.

Emerging experimental evidence indicates that circulating mesenchymal precursors may contribute significantly to vascular remodeling processes (12). The development of vascular remodeling likely requires lung infiltration of mononuclear phagocytic cells. Depletion of circulating monocytic cells by clodronate-containing liposomes (13) prevents $\mathrm{PH}$ in large and small animal models. Recently, several studies have pointed to the importance of fibrocytes, a subpopulation of mononuclear phagocytes, in the development of cancer and inflammatory disorders (14). These cells derive from hematopoietic precursor cells and promote fibrogenic and chronic inflammatory processes (15). Fibrocytes are characterized by expression of CD45 and collagen, and are associated with poor prognosis in patients with idiopathic pulmonary fibrosis (16). In the lung, they are recruited to sites of injury where they participate, directly (produce cytokines) or indirectly (induce resident cells to elicit cytokines) in persistent inflammatory remodeling and proangiogenic signaling (17). Interestingly, use of the stable prostacyclin analogue treprostinil significantly reduced the lung recruitment of fibrocytes in hypoxic mice compared to normoxic mice (18). Treprostinil also reduced right ventricular systolic pressure, slightly reduced the vascular remodeling, but failed to reverse the right 
ventricular hypertrophy in these mice with hypoxic $\mathrm{PH}$. This important study highlights the possibility that measurement and therapeutic targeting of circulating fibrocytes might represent a promising frontier in clinical management of pulmonary hypertension.

Since circulating fibrocytes are elevated in adults with chronic inflammation, and since chronic inflammation is associated with $\mathrm{PH}$, we hypothesized that children and young adults with $\mathrm{PH}$ would manifest increased numbers of blood fibrocytes. The continual influx of these cells might thereby sustain a cycle of perpetual inflammation and vascular remodeling in the lung. To begin to test this, we used flow cytometry of peripheral blood to quantify the number of fibrocytes in individuals with $\mathrm{PH}$ undergoing treatment with a variety of agents, including prostacyclin analogues, compared to controls. We found significant increases in fibrocytes in $\mathrm{PH}$ blood that correlated with increasing mean pulmonary artery pressure and age. It is concluded that $\mathrm{PH}$ is associated with elevated circulating fibrocytes that might play important roles in vascular remodeling.

\section{Methods}

\section{Subjects and blood collection}

The Colorado Multiple Institutional Review Board approved the study, and consent and assent where appropriate was obtained from all patients. The demographic data for all subjects is presented in Tables 1 and 2. Five milliliters of blood was drawn from the femoral vein during initial cardiac catheterization in all patients. The PAH group consisted of children and young adults initially less than 18 years of age at time of diagnosis with pulmonary hypertension from WHO Classification Group I defined as either idiopathic (IPAH), heritable (HPAH), or associated with congenital heart disease (APAH-CHD) (2). The control group included children less than 18 years of age with a structurally normal heart undergoing heart arrhythmia ablation before the onset of the procedure. All patients undergoing ablation were in normal sinus rhythm at the start of the catheterization when the blood was drawn and had a normal echocardiogram. 


\begin{tabular}{|c|c|c|c|c|c|c|c|c|c|c|c|}
\hline Sex & $\begin{array}{c}\mathrm{PH}, \\
\text { WHO Class }\end{array}$ & $\begin{array}{l}\text { Present } \\
\text { Age, } \\
\text { years }\end{array}$ & $\begin{array}{c}\text { Date of } \\
\text { Diagnosis }\end{array}$ & $\begin{array}{c}\text { mPAP } \\
@ \\
\text { Diagnosis, } \\
\text { mm Hg }\end{array}$ & $\begin{array}{l}\text { Date of } \\
\text { Sample }\end{array}$ & $\begin{array}{c}\text { mPAP } \\
@ \text { Date } \\
\text { of } \\
\text { Sample, } \\
\text { mm Hg }\end{array}$ & $\begin{array}{c}\% \\
\text { Fibro- } \\
\text { cytes }\end{array}$ & $\begin{array}{c}\text { Fibro- } \\
\text { cytes } \\
\left(\times 10^{6}\right) / \mathrm{mL}\end{array}$ & $\begin{array}{c}\mathrm{MCP}- \\
1 \\
\mathrm{pg} / \mathrm{mL}\end{array}$ & $\begin{array}{c}\text { SDF- } \\
1 \\
\mathrm{pg} / \mathrm{mL}\end{array}$ & $\begin{array}{l}\text { Medications } \\
\text { at Transition }\end{array}$ \\
\hline $\mathrm{F}$ & $\mathrm{iPAH}, 1$ & 20 & $2 / 7 / 07$ & 32 & $7 / 14 / 10$ & 30 & 0.9 & 0.21 & 218 & 2360 & Ca blocker \\
\hline M & $\mathrm{iPAH}, 2$ & 15 & 9/25/95 & $n / a$ & $7 / 14 / 10$ & 37 & 7.05 & 0.7 & 376.3 & 1394.4 & $\begin{array}{c}\text { Sildenafil } \\
\text { +Remodulin(IV) } \\
\text { +Ambrisentan }\end{array}$ \\
\hline $\mathrm{F}$ & $\mathrm{iPAH}, 2$ & 9 & $6 / 29 / 05$ & 90 & $7 / 14 / 10$ & 28 & 4.23 & 0.55 & 201.5 & 2004 & $\begin{array}{c}\text { Flolan } \\
+ \text { Ambrisentan } \\
\end{array}$ \\
\hline $\mathrm{F}$ & SPAH,2 & 15 & $5 / 21 / 99$ & $n / a$ & 7/15/10 & 54 & 3.8 & 0.42 & 242.6 & 1370.1 & $\begin{array}{c}\text { Tadalafi } \\
\text { +Remodulin(IV) } \\
\text { +Ambrisentan }\end{array}$ \\
\hline $\mathrm{M}$ & SPAH,4 & 19 & $3 / 21 / 02$ & 54 & $7 / 15 / 10$ & 55 & 7.49 & 0.75 & 271.7 & 1826.8 & $\begin{array}{c}\text { Tadalafil } \\
\text { +Flolan } \\
+ \text { Ambrisentan } \\
\end{array}$ \\
\hline $\mathrm{F}$ & $\mathrm{sPAH}, 2$ & 15 & $5 / 15 / 02$ & 71 & $7 / 21 / 10$ & 51 & 6.74 & 0.65 & 243 & 2022 & $\begin{array}{l}\text { Tadalafil } \\
+ \text { Tyvaso } \\
\end{array}$ \\
\hline $\mathrm{F}$ & $\mathrm{iPAH}, 2$ & 10 & $10 / 7 / 08$ & 58 & $7 / 21 / 10$ & 35 & 4.54 & 0.56 & 396.2 & 1909.8 & $\begin{array}{c}\text { Tadalafil } \\
+ \text { Ambrisentan }\end{array}$ \\
\hline $\mathrm{M}$ & $\mathrm{sPAH}, 3$ & 17 & $10 / 6 / 92$ & $n / a$ & 8/11/10 & 43 & 1.13 & 0.26 & 322.1 & 2260 & $\begin{array}{l}\text { Tadalafil } \\
+ \text { Tyvaso } \\
\end{array}$ \\
\hline $\mathrm{F}$ & sPAH,1 & 12 & $11 / 21 / 01$ & 19 & 8/11/10 & 23 & 6.3 & 0.43 & 353.4 & 2272 & Ca blocker \\
\hline $\mathrm{F}$ & SPAH,1 & 9 & $2 / 1 / 07$ & 56 & 8/11/10 & 18 & 1.3 & 0.19 & 202.5 & 1530.6 & $\begin{array}{c}\text { Sildenafil } \\
\text { +Ambrisentan } \\
\text { +Ca blocker }\end{array}$ \\
\hline $\mathrm{M}$ & $\mathrm{iPAH}, 2$ & 2 & $8 / 20 / 08$ & $\mathrm{n} / \mathrm{a}$ & 8/18/10 & 17 & 0.15 & 0.11 & 305.5 & 1175 & $\begin{array}{c}\text { Sildenafil } \\
+ \text { Remodulin(IV) }\end{array}$ \\
\hline $\mathrm{M}$ & $\mathrm{iPAH}, 1$ & 15 & $8 / 1 / 00$ & $\mathrm{n} / \mathrm{a}$ & 8/18/10 & 20 & 1.9 & 0.16 & 350 & 2764 & $\begin{array}{c}\text { Tadarafil } \\
\text { +iloprost } \\
+ \text { Ambrisentan } \\
\end{array}$ \\
\hline $\mathrm{F}$ & $\mathrm{sPAH}, 2$ & 12 & $5 / 19 / 05$ & $\mathrm{n} / \mathrm{a}$ & 8/18/10 & 37 & 1.65 & 0.17 & 202.6 & 2408 & $\begin{array}{c}\text { Sildenafil } \\
+ \text { +Bosentan } \\
\end{array}$ \\
\hline $\mathrm{F}$ & sPAH,1 & 5 & $8 / 26 / 09$ & 38 & $8 / 25 / 10$ & 26 & 5.68 & 0.49 & 343.8 & 1732 & Ca blocker \\
\hline $\mathrm{F}$ & $\mathrm{iPAH}, 1$ & 3 & 9/20/07 & $\mathrm{n} / \mathrm{a}$ & $8 / 25 / 10$ & 24 & 3.8 & 0.36 & 376.9 & 1886.2 & Sildenafil \\
\hline M & SPAH,2 & 13 & 10/11/01 & 73 & $8 / 25 / 10$ & 56 & 14.2 & 0.85 & 377.3 & 1963.2 & $\begin{array}{c}\text { Sildenafil } \\
\text { +Remodulin(IV) } \\
\text { +Ambrisentan }\end{array}$ \\
\hline $\mathrm{F}$ & SPAH,3 & 18 & $3 / 1 / 96$ & $n / a$ & $9 / 8 / 10$ & 61 & 7.66 & 0.72 & 330.3 & 2254 & $\begin{array}{c}\text { Sildenafil } \\
\text { +Remodulin(IV) } \\
\text { +Bosentan }\end{array}$ \\
\hline M & $\mathrm{iPAH}, 1$ & 15 & 10/26/05 & 70 & 9/8/10 & 44 & 6.2 & 0.46 & 399.5 & 2414 & $\begin{array}{c}\text { Tadalafil } \\
+ \text { Ambrisentan }\end{array}$ \\
\hline$M$ & $\mathrm{sPAH}, 4$ & 17 & $2 / 19 / 97$ & $\mathrm{n} / \mathrm{a}$ & $10 / 4 / 10$ & 80 & 4.5 & 0.39 & 343 & 2692 & $\begin{array}{c}\text { Tadalafil } \\
\text { +Flolan } \\
\text { +Bosentan } \\
\end{array}$ \\
\hline $\mathrm{M}$ & $\mathrm{sPAH}, 2$ & 22 & $12 / 19 / 95$ & $\mathrm{n} / \mathrm{a}$ & $10 / 13 / 10$ & 32 & 4.5 & 0.46 & 240.2 & 1957.2 & Ambrisentan \\
\hline $\mathrm{M}$ & $\mathrm{iPAH}, 2$ & 10 & $12 / 17 / 04$ & 106 & $10 / 13 / 10$ & 74 & 6.5 & 0.66 & 327.1 & 1791.4 & $\begin{array}{c}\text { Remodulin(IV) } \\
\text { +Tadalafil }\end{array}$ \\
\hline$M$ & SPAH,2 & 4 & $5 / 29 / 07$ & 20 & $10 / 13 / 10$ & 14 & 0.4 & 0.13 & 319.6 & 1904 & None \\
\hline $\mathrm{M}$ & sPAH, 2 & 2 & 10/29/09 & 28 & $10 / 21 / 10$ & 28 & 2.2 & 0.24 & 316.6 & 1495 & sildenafil \\
\hline $\mathrm{M}$ & SPAH,1 & 1 & $12 / 22 / 08$ & $\mathrm{n} / \mathrm{a}$ & $11 / 10 / 10$ & 19 & 0.6 & 0.16 & 212 & 1429.8 & sildenafil \\
\hline $\mathrm{M}$ & $\mathrm{SPAH}, 1$ & 3 & $3 / 8 / 10$ & $\mathrm{n} / \mathrm{a}$ & $11 / 10 / 10$ & 32 & 3 & 0.37 & 382.4 & 1933.6 & sildenafil \\
\hline $\mathrm{F}$ & $\mathrm{iPAH}, 1$ & 11 & 10/10/05 & 48 & $11 / 10 / 10$ & 41 & 4 & 0.46 & 293.2 & 1785.4 & $\begin{array}{c}\text { Tadalafil } \\
+ \text { Bosentan }\end{array}$ \\
\hline
\end{tabular}




\section{Table 1 PH Subjects Data}

Abbreviations used in table 1: $\mathrm{F}$, female; $\mathrm{M}$, male; iPAH, idiopathic pulmonary arterial hypertension; sPAH, secondary pulmonary arterial hypertension; WHO, World Health Organization; mPAP, mean pulmonary artery pressure; $\mathrm{mm} \mathrm{Hg}$, millimeters mercury; n/a, not catheterized at the time; $\mathrm{pg} / \mathrm{mL}$, picograms per milliliter; MCP, monocyte chemoattractant protein; IL, interleukin; SDF, stromal derived factor; TGF, transforming growth factor; Ca, calcium; IV, Intravenous; values mean \pm SD

\begin{tabular}{|c|c|c|c|c|c|c|c|c|c|}
\hline & Sex & Diagnosis & $\begin{array}{c}\text { Present } \\
\text { Age, } \\
\text { years }\end{array}$ & $\begin{array}{c}\text { Date of } \\
\text { Diagnosis }\end{array}$ & $\begin{array}{l}\text { Date of } \\
\text { Sample }\end{array}$ & $\begin{array}{c}\% \\
\text { Fibro- } \\
\text { cytes }\end{array}$ & $\begin{array}{c}\text { Fibro- } \\
\text { cytes } \\
\left(\times 10^{6}\right) / \mathrm{mL}\end{array}$ & $\begin{array}{c}\text { MCP- } \\
1 \\
\mathrm{pg} / \mathrm{mL}\end{array}$ & $\begin{array}{c}\text { SDF- } \\
1 \\
\mathrm{pg} / \mathrm{mL}\end{array}$ \\
\hline 1 & M & WPW & 8 & $2 / 7 / 07$ & $7 / 14 / 10$ & 1 & 0.13 & 195.2 & 1447.6 \\
\hline 2 & M & WPW, closing VSD, no PH & 13 & 9/25/95 & $7 / 14 / 10$ & 0.6 & 0.25 & 272.4 & 2236 \\
\hline 3 & $\mathrm{~F}$ & arrhythmia (SVT) & 10 & $6 / 29 / 05$ & $7 / 14 / 10$ & 0.9 & 0.1 & 267 & 1672.8 \\
\hline 4 & $\mathrm{~F}$ & arrhythmia (SVT) & 17 & $5 / 21 / 99$ & $7 / 15 / 10$ & 0.8 & 0.3 & 293.1 & 1702.4 \\
\hline 5 & M & arrhythmia (SVT) & 14 & $3 / 21 / 02$ & $7 / 15 / 10$ & 0.9 & 0.13 & 242.8 & 1880.2 \\
\hline 6 & $\mathrm{~F}$ & WPW & 9 & $5 / 15 / 02$ & $7 / 21 / 10$ & 1 & 0.32 & 318.7 & 2088 \\
\hline 7 & M & arrhythmia (SVT) & 13 & $10 / 7 / 08$ & $7 / 21 / 10$ & 1 & 0.15 & 273.5 & 2460 \\
\hline 8 & M & WPW & 14 & $10 / 6 / 92$ & $8 / 11 / 10$ & 0.9 & 0.1 & 346.5 & 2496 \\
\hline 9 & $\mathrm{~F}$ & arrhythmia (SVT) & 17 & $11 / 21 / 01$ & $8 / 11 / 10$ & 1 & 0.32 & 259.4 & 1933.6 \\
\hline 10 & M & arrhythmia (SVT) & 14 & $2 / 1 / 07$ & $8 / 11 / 10$ & 0.3 & 0.33 & 302 & 3084 \\
\hline
\end{tabular}

Table 2 Control Subjects Data

Abbreviations used in table 2: F, female; M, male; WPW, Wolff-Parkinson-White syndrome; VSD, ventricular septal defect; SVT, supra ventricular tachycardia; values mean \pm SD

Hemodynamic parameters and echocardiographic data were obtained at the time of initial catheterization, then later at therapeutic assessment. Fresh, never-frozen blood $(5 \mathrm{~mL})$ was prepared without Ficoll gradient as described by Strieter et al. (16). Buffy coat cells were removed from blood centrifuged for 10 minutes at $1200 \mathrm{rpm}$ at room temperature. Following red blood cell lysis by addition of ammonium chloride (0.15 M, pH 7.3), leukocytes were washed, 
verified for viability by trypan blue exclusion, and prepared to a concentration of $1 \times 10^{6} \mathrm{cells} / \mathrm{ml}$ for antibody labeling and flow cytometry.

\section{Flow cytometric analysis}

Cells were labeled for flow cytometry using antibody against CD45-Pacific Blue (PB986, BD Biosciences), fixed and permeabilized per manufacturer's protocol (BD Biosciences Fix/Perm Solution 554714), and then cells were labeled with rabbit anti-human pro-collagen (PICP, Millipore, MAB1913). Secondary antibody (goat anti-rabbit IgG FITC, Milipore AP132F) was applied per manufacturer's protocols. The negative thresholds for CD45-cychrome and FITC isotype control were set using isotype control labeled cells from both normal and $\mathrm{PH}$ subjects exactly as described by Mathai et al (19). All subsequent samples were gated for the CD45+ region. Data was recorded as fibrocyte numbers $/ \mathrm{mL}$ blood and as a percentage of total leukocyte (CD45+) counts. A minimum of 200,000 events was used to generate each histogram. Flow cytometry was performed on a Beckman FC500 utilizing CXP software.

\section{Cytospin and Immunofluorescence}

In separate experiments, cells were re-suspended to $0.5 \times 10^{6}$ cells $/ \mathrm{ml}$, and $200 \mathrm{uL}$ was centrifuged at 800 r.p.m. for 3 minutes. Cytospins were fixed in ice cold 1:1 acetone:methanol for 10 minutes, then rehydrated in phosphate buffer prior to addition of antibody. Prepared cells were stained with antibodies exactly as described above for flow cytometry. Antibody isotype negative controls were included with each sample group, as was pre-adsorption of antibody to its cognate antigen, supplied by the manufacturers. Slides were mounted in Vectashield plus DAPI medium (Vector Labs). Images were acquired at room temperature using a Zeiss Axiovert S100 fitted with Zeiss 20x 0.4 n.a. and $10 \times 0.3$ n.a. objectives and Axiocam camera. Acquisition of images was by Axiovision 4.6 software (Zeiss). Immunopositive cells (green) were 
counted in 5 fields from 3 cytospin preps each from 3 control preps and $3 \mathrm{PH}$ preps, then divided by the total number of DAPI+ cells.

\section{Clinical data}

Charts were reviewed and data from demographics, hemodynamics, and the 6-Minute Walk Test were extracted. All information describing the patient populations is presented in Tables 1 and 2.

\section{Statistical analysis}

All values were expressed as mean +/- SEM. Comparison between groups was performed using GraphPad software (GraphPad Software for Science Inc., San Diego, CA, USA). An unpaired t test was performed for 2 group comparisons while a Pearson $r$ correlation coefficient was utilized to correlate fibrocyte number to clinical and hemodynamic parameters. Statistical significance was defined as $p<0.05$.

\section{Results}

\section{Fibrocyte Quantification}

Circulating fibrocytes are increased in several chronic inflammatory disorders, including fibrotic lung disease in adults (12). Furthermore, higher numbers of these cells correlate with disease severity and poor outcome (16). We hypothesized that children and young adults with severe $\mathrm{PH}$ would harbor higher numbers of circulating fibrocytes. Indeed, we found that those with $\mathrm{PH}$ had significantly higher numbers and percentages of fibrocytes in peripheral blood compared to controls $\left(n=26,0.42 \times 10^{6} \mathrm{CD} 45+\right.$ /procollagen I+ cells/mL $\pm 0.21,4.24 \%$ s.d.3.06 vs. $n=10$, $0.21 \times 10^{6} \mathrm{CD} 45+$ procollagen I+ cells $/ \mathrm{mL} \pm 0.10,0.84 \%$ s.d 0.23 , respectively, Figure 1 analysis, Figure 2A-B quantification). No statistically significant differences were observed in fibrocyte numbers among those with idiopathic $\mathrm{PH}$ compared to secondary $\mathrm{PH}$. No differences 
were observed in fibrocyte numbers among females and males with $\mathrm{PH}$. Individuals untreated or undergoing one treatment (Ca channel blockers, or sildenafil, or ambrisentan) had a mean fibrocyte/CD45+ $\%$ of $3.35 \%$, while for patients treated with two drugs it was $3.90 \%$, and for patients undergoing three or more treatments it was $5.99 \%$. Patients with the most severe disease were those receiving three or more medications.

\section{Fibrocyte Correlation to Clinical and Hemodynamic Parameters}

Fibrocyte numbers showed statistically significant correlation to mean pulmonary artery pressure $(r=0.575, p<0.05)$ and increasing age $(r=0.354, p<0.05)$, (Figure 2C-F). No correlations were found between fibrocyte numbers and either gender, six minute walk distance, plasma brain natriuretic peptide (BNP), or N-terminal pro-brain natriuretic peptide (NT-BNP), or duration of treatment (data not shown). We found no statistically significant differences in plasma levels of monocyte-chemoattractant protein-1 (305.3 $\pm 64.7 \mathrm{vs.} 276.7 \pm 39.7 \mathrm{pg} / \mathrm{mL})$ or stromal derived factor-1 (1943.6 \pm 398.5 vs. $2100.1 \pm 459.9 \mathrm{pg} / \mathrm{mL})$ between those with pulmonary hypertension vs. controls, respectively.

\section{Immunophenotypic Confirmation of Fibrocytes}

We sought to confirm the flow sorting results for fibrocytes from control and $\mathrm{PH}$ subjects. Using the same procedures as for flow cytometry, we verified their phenotype by immunofluorescence. As expected, a percentage of cells from $\mathrm{PH}$ patients but not controls strongly expressed procollagen, thus confirming efficacy of the cytometry protocol (Figure 3).

\section{Discussion}

Based on animal models that implicate fibrocytes in the pathobiology of pulmonary hypertension and on human studies demonstrating increased fibrocyte numbers in patients with interstitial lung disease, we tested the hypothesis that fibrocytes would be increased in the circulation of 
patients with $\mathrm{PH}$. We found a significant enrichment of circulating fibrocytes (defined as $\mathrm{CD}_{4} 5^{+} / \mathrm{Procollagen}^{+}$cells) in patients with pulmonary hypertension compared with control individuals undergoing catheterization for arrhythmia. In addition, we found correlation between fibrocyte counts and mean pulmonary artery pressure as well as age. Taken together with previous findings from our group and others of exuberant decoration of fibrocytes in and around pulmonary vessels in a neonatal calf model of hypoxic $\mathrm{PH}(18,20)$, our data here supports the notion that the presence of these progenitor cells may contribute to pathological pulmonary vascular remodeling in the setting of inflammation. This is the first demonstration that individuals with $\mathrm{PH}$ harbor increased numbers of circulating fibrocytes, a cell type that has been identified in adults with chronic inflammatory disorders and is associated with poor prognosis, inflammation, and tissue remodeling in the lung. Our study might therefore represent the first step in understanding putative pathological roles of fibrocytes in the course of pediatric pulmonary hypertension.

The biology of fibrocytes is rapidly coming into sharper focus. Originally described as a leukocyte subpopulation that effected tissue repair (21), fibrocytes are critically involved in normal wound healing and fibrosis (22). Their differentiation from precursors cells is complex but may be prohibited by bacterial infection through toll like receptor 2 activation (23). In other contexts, fibrocytes can be differentiated to myofibroblast and adipocyte phenotypes, by transforming growth factor beta (24) and peroxisome-proliferator activated receptor gamma (25), respectively. Apart from tissue remodeling, fibrocytes have been negatively implicated in chronic inflammatory conditions. Fibrocytes are mobilized from the bone marrow and accumulate in regions of chronic inflammation, perhaps through the SDF-1/CXCR4 signaling axis (26). In vivo, fibrocytes have been studied in animal models of $\mathrm{PH}$, and are associated with vascular remodeling, elevated pulmonary artery pressures, and accumulation in bronchovascular regions $(4,18)$. Although the extent of monocytic cell influx into the lung has been well documented in adults with $\mathrm{PH}(27)$, ours is the first to quantitatively assess circulating 
fibrocytes in children and young adults with $\mathrm{PH}$. The present study has confirmed that fibrocytes are present in the blood of patients with $\mathrm{PH}$. How or whether fibrocytes contribute to the remodeling of pulmonary vessels in the human condition remains to be determined. A more precise functional characterization of fibrocytes, at least in the clinical setting, is currently hampered by the seeming requirement of (intracellular) collagen as the "gold standard" for fibrocyte identification. Magnetic bead or flow sorting using extracellular markers as surrogates for expression of collagen would obviate the need for fixation and permeabilization of putative fibrocytes, a process incompatible with many downstream functional assays. Recently, fibrocytes isolated from patients with chronic inflammation have been shown to display an activated phenotype (28). Additionally, the expression profile for cultured fibrocytes is distinct from monocytes, macrophages and fibroblasts (29). These findings highlight the complexity of fibrocyte differentiation, the details of which (stem cell, process, temporal mechanics, tissue influence, etc.) remain shrouded in obscurity. Identification of cell surface markers with high specificity for fibrocytes will facilitate studies designed to understand the functional roles of fibrocytes in vivo, as has already been established for serum amyloid $P(30)$. Our group has previously shown that vascular remodeling and inflammation of the rat pulmonary vasculature during hypoxia requires circulating cells of a monocytic/macrophage lineage (13). Use of fibrocyte-specific agonists and antagonists, based on in vitro and in vivo immunophenotyping of surface markers will more sharply define the cell type most responsible for the remodeling.

Correlation analysis between fibrocyte numbers and mean pulmonary artery pressure and increasing age showed a weak but positive relationship. Fibrocyte counts did not correlate with other patient demographic data. The lack of a stronger correlative relationship between fibrocyte count and mean pulmonary artery pressure is not altogether surprising for several reasons. First, the age range of our $\mathrm{PH}$ patient cohort spanned 22 years and had a large standard deviation (+/- 6.18 years). There are no studies available that define linkage between fibrocyte counts and age. We assumed a priori that (young) individuals in the control group would have 
low fibrocyte numbers ( $\leq 1 \%$ of total white blood cells) as is observed in control adults. However, this is an assumption that needs additional testing. In any case, we found low numbers of fibrocytes in peripheral blood of controls, numbers similar to those documented in older controls (16). Second, many of the PH patients in our study are on significantly long standing and varied treatment regimens, including calcium channel blockers, endothelin receptor antagonists, phosphodiesterase inhibitors, and prostanoids. In addition, some of the children responded to acute vasodilator challenge and others did not. As such, the variable clinical presentation and underlying pathobiology (ex: idiopathic vs. $\mathrm{PH}$ associated with congenital heart defect) of our study group likely reduced the power of fibrocyte number to more closely correlate with severity of $\mathrm{PH}$ as measured by mean pulmonary artery pressure. In fact, it remains possible that since treatments with prostacyclin agonists appear to increase the number of late EPCs, such treatment could also lead to mobilization of fibrocytes into the circulation. In future studies, restricting the analysis of circulating fibrocytes to exclude patients with $\mathrm{PH}$ not associated with extensive lung inflammation and remodeling will likely prove fruitful, as will studying patients at diagnosis (untreated). Fibrocytes are involved in both normal wound healing and inflammation but at present we are unable to say which of these mechanisms is involved in these patients. We speculate that it is pro-inflammatory and perhaps the data that the patients with the most severe disease (on triple therapy) also have the highest fibrocyte numbers offers a clue in support of this assumption. This is in contrast to endothelial progenitor cells, which are thought to be decreased with increased severity of $\mathrm{PH}(4-5)$. It is thus plausible that the collective contributions of distinct progenitor cell populations govern lung homeostasis, and by extension, deviation from homeostasis during pathogenesis.

In conclusion, we have shown quantitative differences in circulating fibrocytes between individuals with $\mathrm{PH}$ and without. The fibrocyte count correlated with increased mean pulmonary artery pressure and age. This study suggests a potential role for these cells in the pathogenesis of $\mathrm{PH}$, but more studies are needed to confirm our findings. A great deal of renewed research 
emphasis over the past decade has been placed on mechanisms of lung inflammation and vascular remodeling in pulmonary hypertension. Our study points to the potential contributions of circulating mesenchymal progenitors to those inflammatory processes.

\section{Acknowledgements}

We would like to especially acknowledge the generosity and kindness of Robert Strieter. M.D. in whose lab we learned the techniques used in this report. We also wish to thank Marie Burdick from the Strieter lab for teaching and graciously hosting us. We thank the University of Colorado Cancer Center Flow Cytometry Core for technical assistance.

\section{Support Statement}

This study was funded by an Actelion Entelligence Young Investigator Award (M.E.Y.) and by National Institutes of Health (NIH) Specialized Centers of Clinically Oriented Research (SCCOR) Grant HL-084923-02, NIH Program Project Grant HL-014985-35, the Jayden DeLuca Foundation, M01-RR00069 General Clinical Research Center National Center for Research Resources National Institutes of Health, and the Leah Bult Pulmonary Hypertension Research Fund.

\section{References}

1. Humbert M. Update in pulmonary hypertension 2008. Am J Respir Crit Care Med 2009; 179: 650-656.

2. Barst RJ, Ertel SI, Beghetti M, et al. Pulmonary arterial hypertension: a comparison between children and adults. Eur Respir J 2011; 37: 1-13. 
3. Morrell NW, Adnot S, Archer SL, et al. Cellular and molecular basis of pulmonary arterial hypertension. J Am Coll Cardiol 2009; 54: S20-31.

4. Toshner M, Voswinckel R, Southwood M, et al. Evidence of dysfunction of endothelial progenitors in pulmonary arterial hypertension. Am J Respir Crit Care Med 2009; 180: 780-787. 5. Junhui Z, Xingxiang W, Guosheng F, et al. Reduced number and activity of circulating endothelial progenitor cells in patients with idiopathic pulmonary arterial hypertension. Respir Med 2008; 102: 1073-1079.

6. Smadja DM, Mauge L, Gaussem P, et al. Treprostinil increases the number and angiogenic potential of endothelial progenitor cells in children with pulmonary hypertension. Angiogenesis 2010; 14: 17-27.

7. Asosingh K, Aldred MA, Vasanji A, et al. Circulating angiogenic precursors in idiopathic pulmonary arterial hypertension. Am J Pathol 2008; 172: 615-627.

8. Diller GP, van Eijl S, Okonko DO, et al. Circulating endothelial progenitor cells in patients with Eisenmenger syndrome and idiopathic pulmonary arterial hypertension. Circulation 2008; 117 : 3020-3030.

9. Hall S, Brogan P, Haworth SG, et al. Contribution of inflammation to the pathology of idiopathic pulmonary arterial hypertension in children. Thorax 2009; 64: 778-783.

10. Gambaryan N, Perros F, Montani D, et al. Targeting of c-kit+ hematopoietic progenitor cells prevents hypoxic pulmonary hypertension. Eur Respir J 2011; 37: 1392-1399.

11. Davie NJ, Crossno JT Jr, Frid MG, et al. Hypoxia-induced pulmonary artery adventitial remodeling and neovascularization: contribution of progenitor cells. Am J Physiol Lung Cell Mol Physiol 2004; 286: L668-678. 
12. Stenmark KR, Frid MG, Yeager ME. Fibrocytes: potential new therapeutic targets for pulmonary hypertension? Eur Respir J 2010; 36: 1232-1235.

13. Frid MG, Brunetti JA, Burke DL, et al. Hypoxia-induced pulmonary vascular remodeling requires recruitment of circulating mesenchymal precursors of a monocyte/macrophage lineage. Am J Pathol 2006; 168: 659-669.

14. Sun L, Louie MC, Vannella KM, et al. New concepts of IL-10 induced lung fibrosis: fibrocyte recruitment and M2 activation in a CCL2/CCR2 axis. Am J Physiol Lung Cell Mol Physiol 2010; 300: L341-353.

15. Keeley EC, Mehrad B, Strieter RM. Fibrocytes: bringing new insights into mechanisms of inflammation and fibrosis. Int J Biochem Cell Biol 2010; 42: 535-542.

16. Moeller A, Gilpin SE, Ask K, et al. Circulating fibrocytes are an indicator of poor prognosis in idiopathic pulmonary fibrosis. Am J Respir Crit Care Med 2009; 179: 588-594.

17. Lama VN, Phan SH. The extrapulmonary origin of fibroblasts: stem/progenitor cells and beyond. Proc Am Thorac Soc 2006; 3: 373-376.

18. Nikam VS, Schermuly RT, Dumitrascu R, et al. Treprostinil inhibits the recruitment of bone marrow-derived circulating fibrocytes in chronic hypoxic pulmonary hypertension. Eur Respir J 2010; 36: 1302-1314.

19. Mathai SK, Gulati M, Peng X, et al. Circulating monocytes from systemic sclerosis patients with interstitial lung disease show an enhanced profibrotic phenotype. Lab Invest 2010; 90: 812823.

20. Frid MG, Li M, Gnanasekharan M, et al. Sustained hypoxia leads to the emergence of cells with enhanced growth, migratory, and promitogenic potentials within the distal pulmonary artery wall. Am J Physiol Lung Cell Mol Physiol 2009; 297: L1059-1072.

21. Bucala R, Spiegel LA, Chesney J, et al. Circulating fibrocytes define a new leukocyte subpopulation that mediates tissue repair. Mol Med 1994; 1: 71-81. 
22. Bellini A, Mattoli S. The role of the fibrocyte, a bone marrow-derived mesenchymal progenitor, in reactive and reparative fibroses. Lab Invest 2007; 87: 858-870.

23. Maharjan AS, Pilling D, Gomer RH. Toll-like receptor 2 agonists inhibit human fibrocyte differentiation. Fibrogenesis Tissue Repair 2010; 3: 23.

24. Wang $\mathrm{CH}$, Huang $\mathrm{CD}$, Lin $\mathrm{HC}$, et al. Increased circulating fibrocytes in asthma with chronic airflow obstruction. Am J Respir Crit Care Med 2008; 178: 583-591.

25. Hong KM, Belperio JA, Keane MP, et al. Differentiation of human circulating fibrocytes as mediated by transforming growth factor-beta and peroxisome proliferator-activated receptor gamma. J Biol Chem 2007; 282:22910-22920.

26. Song JS, Kang CM, Kang HH, et al. Inhibitory effect of CXC chemokine receptor 4 antagonist AMD3100 on bleomycin induced murine pulmonary fibrosis. Exp Mol Med 2010; 42: 465-472.

27. Stenmark KR, Davie NJ, Reeves JT, et al. Hypoxia, leukocytes, and the pulmonary circulation. J Appl Physiol. 2005; 98: 715-721.

28. Galligan CL, Siminovitch KA, Keystone EC, et al. Fibrocyte activation in rheumatoid arthritis. Rheumatology (Oxford) 2010; 49: 640-651.

29. Pilling D, Fan T, Huang D, et al. Identification of markers that distinguish monocyte-derived fibrocytes from monocytes, macrophages, and fibroblasts. PLoS One 2009; 4: e7475.

30. Pilling D, Roife D, Wang M, et al. Reduction of bleomycin-induced pulmonary fibrosis by serum amyloid P. J Immunol 2007; 179: 4035-4044. 


\section{Figures}

Figure 1 Representative flow cytometric analysis for circulating CD45+/procollagen+ cells in controls and PH patients. (A) CD45-PB vs. intracellular isotype control-FITC analysis on blood from a representative normal subject. This control was used to set negative gates. $x$ axis: IgGk FITC isotype. y axis: anti-CD45-PB. (B) CD45+/procollagen+ cells in normal blood. $x$ axis: procollagen stained with goat anti-rabbit-FITC secondary antibody. y axis: anti CD45-PB. (C) CD45-PB vs. intracellular isotype control-FITC analysis on blood from a patient with $\mathrm{PH}$. This control was used to set negative gates for the $\mathrm{PH}$ sample, same axes as in panel a. (D) CD45+/procollagen+ cells in PH blood, same axes as in panel b. (E) SSC vs. FSC analysis of buffy coat cells from the sample in panel $\mathrm{d}$. SSC $=$ side scatter, FSC $=$ forward scatter. FITC $=$ Fluorescein isothiocyanate; $\mathrm{PB}=$ pacific blue; $\mathrm{PICP}=$ procollagen

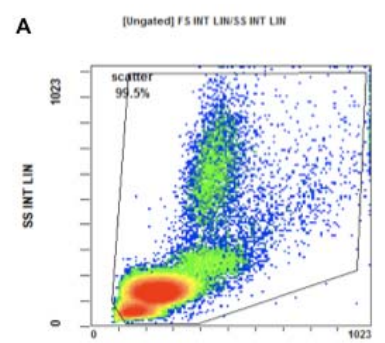

Fs mit um
B

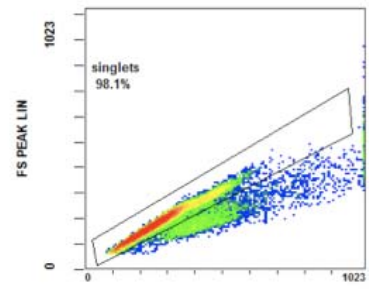

C

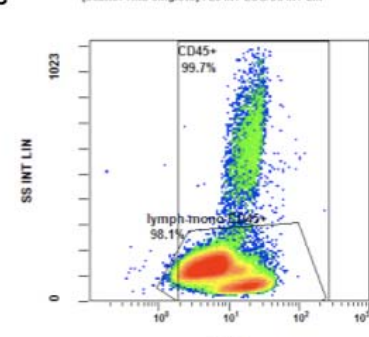

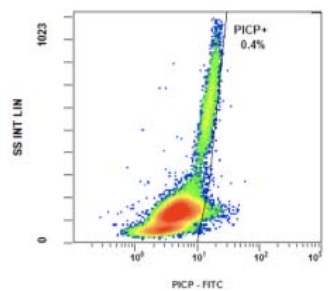

E

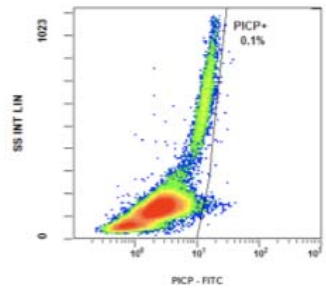

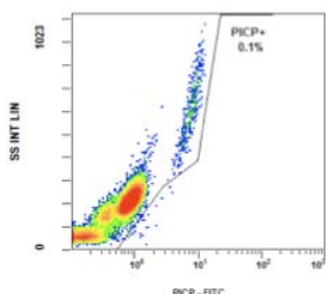

G

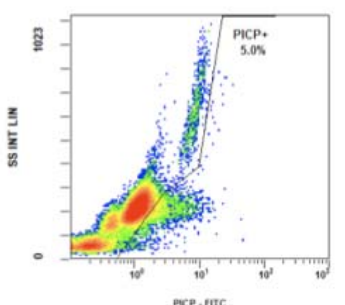

Figure 1 Representative flow cytometric analysis for fibrocytes. (A) Total cell population selected on unstained cells. (B) Selection of singlet only population. (C) Isotype control for $\mathrm{CD} 45$ set on unstained cells. (D-E) Control individual. (D) Isotype control for pro-collagen (PICP) set on the CD45-gated population, $n=$ 50,000 . (E) Positive population for CD45 and PICP, $n=30$. This control individual has $0.06 \%$ fibrocytes. (F-G) Patient with pulmonary hypertension. ( $F$ ) Isotype control for PICP set on the CD45-gated population, $n=48,996$. (G) Positive population for $C D 45$ and PICP, $n=2449,5 \%$, from a patient with pulmonary hypertension. FITC $=$ Fluorescein isothiocyanate; FSC-A = forward scatter; SSC-A $=$ side scatter 
Figure 2 Circulating fibrocytes are enriched in pulmonary hypertension compared to controls and correlate to mean pulmonary artery pressure and age. Fibrocyte counts for $n=10$ controls and $n=26 \mathrm{PH}$ patients were $(\mathrm{A}) 0.84 \% \pm 0.23$ vs. $4.24 \% \pm 3.06$, and $\mathrm{B}) 0.21 \times 10^{6}$ CD45+/procollagen I+ cells $/ \mathrm{mL} \pm 0.10$ vs. $0.42 \times 10^{6} \mathrm{CD} 45+/$ procollagen $\mathrm{I}+$ cells $/ \mathrm{mL} \pm 0.21$ respectively. (C-F) Analysis of correlation of fibrocyte $\%$ and cell counts in patients with pulmonary hypertension to (C-D) mean pulmonary artery pressure $(r=0.575$ for $\%$ and $r=$ 0.695 for numbers) and (E-F) age ( $r=0.354$ for $\%$ and $r=0.401$ for numbers). Note that the correlation between age and fibrocytes expressed as a percentage (E) did not reach significance at alpha $.05 .{ }^{*}=p<0.05$ vs. control
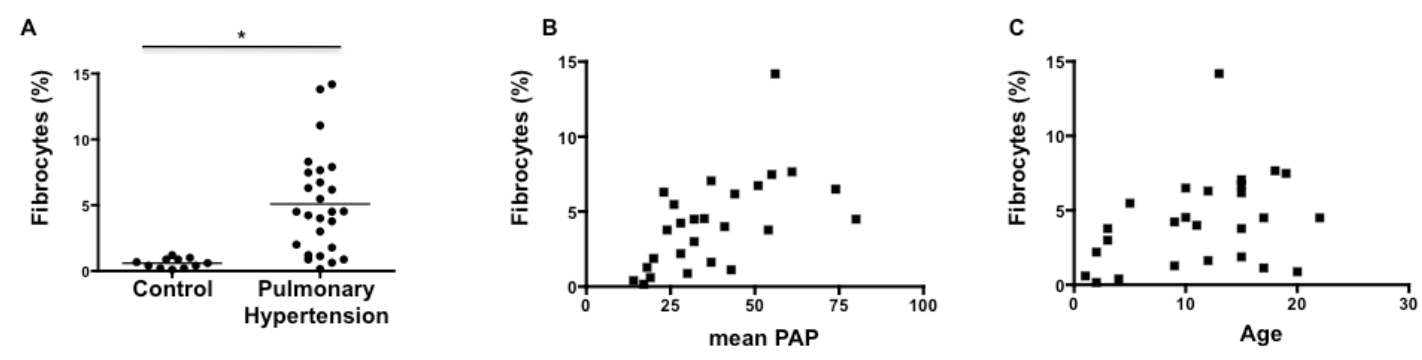

D
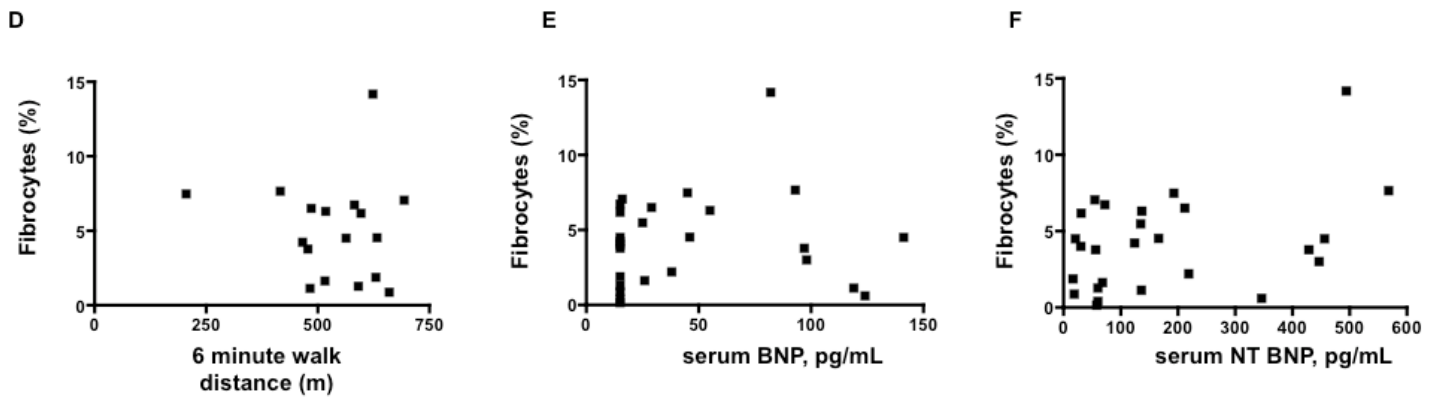

Figure 2 Circulating fibrocyte cell counts are significantly higher in pediatric pulmonary hypertension compared to controls and correlate to mean pulmonary artery pressure and age. (A) Mean fibrocyte counts are $0.6 \% \pm 0.37 \% ; n=10$ in control subjects, and $(5.09 \% \pm 3.85 \% ; n=26)$ in patients with PH. (B-F) Analysis of correlation of fibrocyte cell counts in patients with pulmonary hypertension to $(B)$ mean pulmonary artery pressure $(r=0.575, p<0.05)$, (C) age $(r$ $=0.354, p<0.05),(D) 6$ minute walk test distance, $(E)$ serum brain natriuretic peptide, $(F)$ serum NT brain natriuretic peptide. ${ }^{*}=p<0.05$ vs. control 
Figure 3 Immunofluorescent analysis of circulating fibrocytes. Equivalent numbers of cytospun buffy coat cells were examined from controls and individuals with $\mathrm{PH}$ for expression of procollagen (PINP, Alexa-488, arrows; counterstain DAPI).
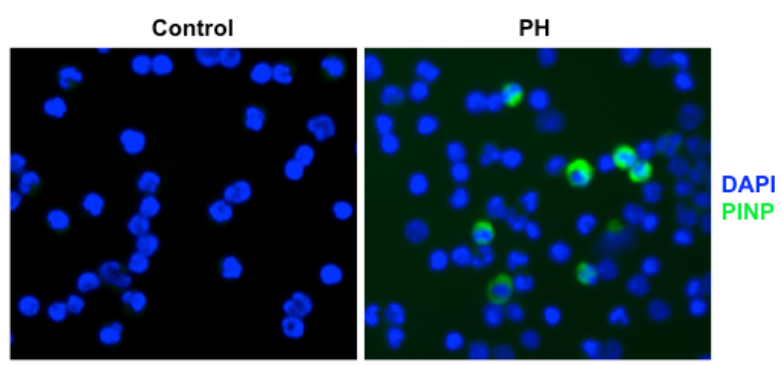

Figure 3 Immunofluorescent analysis of circulating fibrocytes. Equivalent numbers of flow sorted cytospun buffy coat cells were examined from controls and children with PH for co-expression of procollagen (PINP, Alexa-488) 